\title{
A imaginação romântica como neurose? $\bigcirc$ debate freudiano sobre o animismo e a questão do olhar em E. T. A. Hoffmann
}

\author{
[The romantic imagination as neurosis? The Freudian debate on animism and the \\ question of sight in E. T. A. Hoffmann]
}

http://dx.doi.org/10.11606/1982-88372238122

\author{
Felipe Vale da Silva ${ }^{1}$ \\ Sabrine Ferreira da Costa ${ }^{2}$
}

\begin{abstract}
This paper takes up Freud's analysis of Der Sandmann (1816), embodied in a 1919 article which proved itself paradigmatic to interpretations of E. T. A. Hoffmann's work. In this article, the father of psychoanalysis renders several judgments about the argumentative structure of the romantic novella which, in Literary Studies, have been improperly attributed to Hoffmann himself. His aesthetical program would namely be one of an analyst of psychical mechanisms of his characters, thus revealing the author as an odd pundit of psychoanalytic theories much before their inception. It is as if the setup of the horrifying fantasy which characterizes his prose should come along an interpretative urge of the hidden areas of the psyche, so as to discredit irrational and animist tendencies in his characters. Freud's critique of animism is one of the most contested by recent scholar such as Bruno Latour and Isabelle Stengers. Hence, some of their arguments will be recovered at a second moment of this article in order that we go back to Hoffmann and reinterpret his aesthetics as a defense of a certain type of animism, beyond the psychoanalytic paradigm that never ceased to overshadow it.
\end{abstract}

Keywords: Sigmund Freud; E. T. A. Hoffmann; Romanticism; animism; anti-fetishism; Uncanny.

Resumo: O trabalho retoma a análise freudiana de Der Sandmann, presente num ensaio de 1919 que se provou paradigmático para as interpretações futuras da obra de E. T. A. Hoffmann. No dito ensaio, o pai da psicanálise faz diversos juízos sobre a construção argumentativa da novela romântica que, nos estudos literários, vêm sendo indevidamente atribuídos ao próprio Hoffmann. Seu programa estético supostamente seria aquele de um analista dos mecanismos psíquicos de suas personagens, revelando-o como um curioso conhecedor avant la lettre das teorias psicanalíticas. É como se a criação de um imaginário horripilante que caracteriza sua prosa

1 Universidade Federal de Goiás, R. Santo Amaro, 563, Goiânia, GO, 74605220, Brasil. E-mail: felipe.vale.silva@gmx.com. ORCID: 0000-0002-2146-6550

${ }^{2}$ Universidade de São Paulo, Avenida Luciano Gualberto, 403, São Paulo, SP, 055080010, Brasil. E-mail: sabrine.costa@usp.br.

\section{(cc) BY-NC}


SILVA, F.; COSTA, S.F. - A imaginação romântica como neurose?

servisse a um impulso interpretativo das áreas ocultas da psique a fim de detrair tendências irracionalistas e animistas de suas personagens. A crítica freudiana ao animismo é um dos aspectos mais contestados por estudiosos recentes como Bruno Latour e Isabelle Stengers e, por isso, retomaremos seus argumentos num segundo momento. Então, alguns de seus argumentos serão retomados em um segundo momento do artigo para que possamos voltar a Hoffmann e reinterpretar sua estética como uma defesa de certo tipo de animismo, para além dos paradigmas psicanalíticos que nunca cessaram de o ensombrar.

Palavras-chave: Sigmund Freud; E. T. A. Hoffmann; Romantismo; animismo; antifetichismo; insólito.

« Comme elle [l'imagination] a créé le monde $[\ldots]$, il est juste qu'elle le gouverne. »

Charles Baudelaire

No futuro, Freud será lembrado antes como um ensaísta brilhante do que como inventor de uma terapia, afirmou Harold Bloom (1994: 182) em um ensaio polêmico. A afirmação não deveria soar como uma desqualificação do edifício conceitual criado pelo pai da psicanálise, mas como uma tentativa de ressaltar a qualidade de sua obra ensaística. De seus ensaios, O Insólito (Das Unheimliche; ver FrEUD, 2012 [1919]) é incontestadamente o mais comentado e o mais abrangente (DIERKS 2006: 204). ${ }^{3}$ Num texto relativamente curto -27 páginas na primeira edição publicada pela revista Imago $^{4}$ - teóricos já encontraram contribuições para um grande número de áreas do conhecimento:

(1) psicanalistas como Otto Fenichel e Jacques Lacan localizaram nele um tratamento importante para a teoria do recalque (Verdrängung);

(2) filósofos e críticos literários como o supracitado Harold Bloom o enxergaram como "a única grande contribuição no século XX para a estética do sublime" (como desenvolve ROYLE, 2003: 14);

\footnotetext{
3 Adiantemos que optamos pela palavra "insólito" (e não "inquietante" ou "estranho", como muitos tradutores fizeram; ver FREUD 2010 e 1996) pela aproximação de sua etimologia com o sentido que Freud confere ao termo. Insolitus, no latim, deriva da junção entre o prefixo de negação in- e sodeō (habitual) que, por sua vez, deriva do protoindo-europeu *swé ("próprio") + * $\mathrm{d}^{\mathrm{h}} \mathrm{h}_{1}$ - ("localizar, pôr, situar"). Algo insólito é aquilo que o indivíduo reconhece como sendo de fora de seu âmbito, algo inquietante. Por outro lado, remete meramente a um elemento que perturba o ânimo do sujeito.

${ }^{4}$ Referência da edição original: "Imago: Zeitschrift für Anwendung der Psychoanalyse auf die Geisteswissenschaften" (1919).
} 
SILVA, F.; COSTA, S.F. - A imasinação romântica como neurose?

(3) antropólogos (Clifford Geertz, Margaret Mead, Gregory Bateson) retiraram de suas páginas uma teoria da imaginação animista relevante para a antropologia da religião e aos estudos de culturas estrangeiras;

(4) por fim, para os estudos literários, o texto é de sumo interesse, visto tratar de uma novela de E. T. A. Hoffmann - até hoje, o texto mais lido e discutido do escritor romântico (DIERKS 2006: 206) - e automaticamente gerar uma renascença dessa figura nos departamentos de literatura de todo o mundo.

Evidentemente, esta última é a perspectiva pertinente para o restante deste artigo. Partamos da consideração de que Freud foi um dos primeiros a criar um paradigma interpretativo rigoroso para a obra de Hoffmann que, até aquele momento, era visto como um "eterno diletante" a respeito do qual "ninguém soube como começar a falar por quase cem anos" (GÜNZEL 1984: 7-8). ${ }^{5}$ Em meio aos outros poetas românticos alemães, muitos dos quais começaram vanguardistas e acabaram ultraconservadores católicos, ${ }^{6}$ sobressaía o multiartista desordeiro e ofensivo ao bom tom da sociedade alemã oitocentista que, mesmo alcoólatra e celebrador dos excessos, manteve-se no cânone em função de sua influência direta sobre outros tantos “desajustados” da literatura, dentre eles Edgar Allan Poe, Álvares de Azevedo e Charles Baudelaire. ${ }^{7}$

O fato de o Hoffmann pós-1919 ter sido produto da interpretação de Sigmund Freud trouxe duas implicações para os estudos sobre o autor, as quais mencionaremos aqui sem muitos pormenores. Em primeiro lugar, consolidou a ideia de que seu programa estético era aquele de um analista dos mecanismos psíquicos de suas personagens, revelando-o na qualidade de um curioso conhecedor avant la lettre das teorias freudianas da dinâmica do trauma. É como se a criação de um imaginário horripilante que caracteriza um texto tal qual O Homem da Areia (Der Sandmann, 1816), sobretudo, servisse a uma força maior, a uma espécie de impulso analítico das áreas ocultas da psique humana.

\footnotetext{
${ }^{5}$ Doravante, todas as traduções serão dos articulistas: "[dieser] ewige Dilettant [...], die [man] auch fast hundert Jahre lang nicht viel mit ihm anzufangen wußte." Sobre história da recepção do texto, ver Herrmann (2015: 51).

${ }^{6}$ Os exemplos são muitos: Friedrich Schlegel, Novalis, Joseph von Eichendorff, Clemens Brentano, Ludwig Achim von Arnim, Ernst Moritz Arndt (um não-católico, mas antissemita virulento), Sophie Mereau.

${ }^{7} \mathrm{O}$ julgamento (bastante moralista) da conduta de Hoffmann foi produto, sobretudo, da crítica que se estende do século XIX até o final do Nacional-socialismo, apesar do interesse editorial constante por suas obras. O biógrafo Klaus Günzel trata de diferentes imagens do autor para a crítica no início do estudo Hoffmann. Leben und Werk in Briefen Selbstzeugnissen und Zeitdokumenten (1984).
} 
SILVA, F.; COSTA, S.F. - A imaginação romântica como neurose?

Um tal impulso nos leva, na condição de leitores, a decifrarmos o emaranhado de imagens/temas presentes nesta novela como se fosse um verdadeiro tratado sobre o declínio mental do protagonista Nathanael - alguns dos temas são: olhos, espelhos, fragmentação, autômatos e loucura (DIERKS 2006: 206). O jovem protagonista é constantemente atormentado por sua imaginação, uma vez que é remetido a lembranças do passado. Conta-se que o pai morreu há tempos num estranho acidente alquímico (evento pouco claro na mente do protagonista) e imagens da experiência traumática não cessam de voltar-lhe à mente. Do evento, somente um advogado chamado Coppelius saíra ileso. Ao encontrar um homem parecido com esse antigo conhecido do pai, Nathanael tem uma recaída traumática. Na leitura de Freud (2012), a falta da presença de uma figura paterna leva Nathanael a personificar seu próprio desenvolvimento sexual irregular na aparição do tal Homem da Areia, figura macabra do folclore, sobre a qual ouvira de uma babá na infância e que liga a Coppelius. Por nunca conseguir dar um passo à frente, livrando-se de ilusões paranoicas e medos irracionais, Nathanael torna-se uma pessoa improdutiva e controlada pela própria neurose. Em vez de manter um relacionamento saudável com uma mulher real (a noiva Clara), ele se apaixona por uma boneca de madeira, Olimpia (ver Freud 2012: 33, nota 4). Por fim, torna-se violento e rende-se ao suicídio.

O nome que Freud dá a tal sentimento de eterna volta do mesmo, de estranho deslocamento diante das coisas triviais, é das Unheimliche ("o insólito", vide nota de rodapé 1), conceito importante que será tratado adiante. O que para pessoas saudáveis é algo trivial - um exemplo no texto é a imagem recorrente de olhos -, para Nathanael é um gatilho para devaneios e retorno de conteúdos recalcados. Freud (2012) interpreta a perda dos olhos como um motivo constante, não apenas em Hoffmann, mas no que ele considera cultura universal, perda que representaria um medo instintivo compartilhado por toda a humanidade. Ao ouvir a historieta sobre o homem da areia - um conto de fadas de fato narrado às crianças alemãs, pelo menos desde o século XVIII, em que uma entidade vem lhes roubar os olhos caso não durmam quando devem -, Nathanael extrapola a monstruosidade do ser fictício e o conecta a suas próprias ansiedades pessoais. O homem da areia se torna duplo de Coppelius, suposto assassino de seu pai (FALKENBERG 2005: 68; HERRMANN 2015: 49). É numa formulação bastante vaga que Freud conclui: “o estudo dos sonhos, das fantasias e dos mitos nos ensinou que o medo relativo aos olhos, o medo de ficar cego, é frequentemente um substituto para o medo da castração" (FREUD 2012: 
SILVA, F.; COSTA, S.F. - A imaginação romântica como neurose?

14). ${ }^{8}$ Uma consideração sem grandes implicações para um estudo de caráter literário, ainda que seja repetidamente citada nos tratamentos da referida obra hoffmanniana, como se nela estivesse contida, de forma inquestionada - mencionemos exemplos de articulistas recentes no Brasil: Santos (2009), Falcato (2012), Medina (2017) e Oliveira (2017). O autor romântico parece se tornar, insolitamente, um alter ego de Freud por força da repetição de uma comunidade de leitores. E mais: se pensarmos Hoffmann como uma espécie de veiculador involuntário da terapêutica freudiana, ele ganha estranhos contornos de um defensor da estabilidade mental, inimigo de tendências irracionalistas e animistas de suas personagens. Basta lermos seus livros detidamente para vermos que aqui há um contrassenso. Ainda que a criação de uma imagem invertida do autor berlinense sirva como atestado do poder (e longevidade) da criatividade freudiana, é preciso investigar a interpretação do Hoffmann subjacente à formulação do conceito psicanalítico.

Em segundo lugar, cabe questionarmos: será que as críticas do século XXI feitas contra conceitos freudianos, sobretudo aquelas relativas à sua noção de animismo, podem ser estendidas a Hoffmann? Na crítica mais recente de Latour (2002), que será retomada mais para frente, Freud é criticado por situar a mentalidade altamente imaginativa - a dos animistas - numa posição inferior na escala de evolução cultural e intelectual, retratandoa como uma "concepção de mundo antiga", caracterizada pelo "preenchimento do mundo com espíritos dos homens" (FREUD 2012: 21), ${ }^{9}$ que nos leva a fazer deduções ilógicas quando uma coincidência ou algo inesperado, por exemplo, ocorrem. Trata-se, justamente, do que se passa com as personagens instáveis de Hoffmann; Nathanael imagina estar sendo perseguido por um homem demoníaco interessado em roubar seus olhos e dá-los como alimento para os próprios filhos, uma fantasia absurda que o psicanalista atribui ao trauma de infância já mencionado. Essa seria ainda uma manifestação de um estado narcísico próprio de crianças pequenas ou seres ditos primitivos para os quais há uma linha tênue entre o $I d$ e o Ego. "O infantil nisso tudo, o que também domina a vida anímica do neurótico, é a superênfase na realidade psíquica

\footnotetext{
8 “"...] das Studium der Träume, der Phantasien und Mythen hat uns dann gelehrt, daß die Angst um die Augen, die Angst zu erblinden, häufig genug ein Ersatz für Kastrationsangst ist".

9 "Eine alte Weltauffassung durch die Erfüllung der Welt mit Menschenseelen."
} 
SILVA, F.; COSTA, S.F. - A imaginação romântica como neurose?

em detrimento da material, um traço que se associa à onipotência do pensamento" (Ibidem: 25). ${ }^{10}$

“A onipotência do pensamento", i.e. do que se passa na cabeça do neurótico: aqui temos o caso "problemático" de alguém que não se rende às rigorosas regras da realidade empírica. O neurótico se encontra doente por agir como o homem primitivo, como um animista. Um dos corretivos para tal erro de dedução, por conseguinte, seria o aperfeiçoamento de seu conhecimento científico (Ibidem: 22): o reconhecimento de que não há deuses, demônios ou ligações espirituais agindo ao nosso redor, mas apenas a banalidade da vida humana. No caso de Nathanael, faltou-lhe aceitar que o pai morrera em função de um acidente trivial, ainda que trágico e significante para a sua existência, especificamente. Mas isso não implica que haja de fato uma entidade demoníaca que possa ser culpada pela destruição de sua família.

Latour (2002: 25-27) considera a postura de Freud antifetichista, ou seja, contrária à atribuição do poder de autodeterminação imanente ao indivíduo a objetos/entidades externas e, muitas vezes, imaginárias. Mantenhamos esse termo em segundo plano para responder, após uma análise detida dos textos, se Hoffmann foi de fato um antifetichista como Freud. A sugestão é, ao contrário, que a criação do imaginário romântico pode ser melhor entendida como um esforço para revitalizar o animismo. Para argumentar nesse sentido, explicando do que se trata o "animismo hoffmanniano", defenderemos inicialmente como Freud cita literatura para exemplificar suas próprias teorias e não recriar o processo criativo de um escritor, seja lá quem for. ${ }^{11}$

O embate de Freud acerca de $O$ Homem da Areia deriva de um contexto bastante específico de disputa entre sua própria teoria do insólito e a de Ernst Jentsch. De fato, até mesmo sua escolha por esta novela não advém de uma convicção teórica de que tal obra representaria melhor a produção artística de Hoffmann. Antes, Freud parece optar por ela em razão de seu texto ser uma resposta a um ensaio mais antigo, Sobre a psicologia do

\footnotetext{
10 "Das Infantile daran, was auch das Seelenleben der Neurotiker beherrscht, ist die Überbetonung der psychischen Realität im Vergleich zur materiellen, ein Zug, welcher sich der Allmacht der Gedanken anschließt." A formulação é uma repetição daquela presente no texto mais antigo, Totem e Tabu. (ver FREUD 1922: 115, nota de rodapé 104)

${ }^{11}$ De fato, E. T. A. Hoffmann é apenas um dentre 11 escritores de ficção mencionados em $O$ Insólito, cada qual com sua própria estética. Os demais são: Friedrich Maximilian von Klinger, Wilhelm Hauff (mencionado três vezes), Oscar Wilde, William Shakespeare, Johann Nestroy, Homero, Arthur Schnitzler, Hans Christian Andersen, Friedrich Schiller e Albrecht Schaeffer, um escritor pouco lido até hoje, mas que, por ser amigo pessoal de Freud, era geralmente elencado nos ensaios deste ao lado de grandes nomes da literatura. A fortuna crítica de todos esses outros autores não toma o ensaio freudiano como paradigma interpretativo de obras de ficção, vale dizer.
} 
SILVA, F.; COSTA, S.F. - A imaginação romântica como neurose?

insólito, de Ernst Jentsch (Zur Psychologie des Unheimlichen, 1997, [1906]). É Jentsch, na verdade, quem escolhe a obra em questão.

\section{$1 \bigcirc$ início da discussão: o debate Freud-Jentsch}

“Aqui não será feita uma tentativa de definir a essência do insólito", Ernst Jentsch afirma no início do artigo publicado em duas partes, em 25 de agosto e $1^{\circ}$ de setembro de 1906 (JENTSCH 1997: 8). ${ }^{12}$ Isso porque ele teria vivenciado a experiência com seus pacientes de que "uma mesma impressão não necessariamente acarreta um efeito insólito em todas as pessoas" (idem). ${ }^{13} \mathrm{O}$ fenômeno é abrangente demais e dependente demais do imaginário do paciente para que seja possível dar uma explicação definitiva para suas origens. A grande questão para Jentsch foi a de investigar como a excitação afetiva causada pelo insólito se dá em termos estritamente psicológicos (op. cit.: 9). Ele estaria interessado em manifestações nervosas que derivam - repito aqui seu exemplo - do encontro de um indivíduo com um autômato, uma espécie de robô movido por mecanismos não-elétricos: estando acostumada com a divisão natural entre seres inanimados e seres vivos, uma pessoa desavisada que visse um autômato de madeira exercendo funções humanas seria acometida por um estranho sentimento. A qualidade de tal experiência é o que popularmente chamava-se de insólito (unheimlich).

Jentsch se vale da etimologia da palavra alemã, que contém o prefixo de negação un- mais o termo "lar" (heim, como home do inglês) e o faz para fins explicativos: unheimlich é algo com o qual não nos sentimos em casa, que causa estranhamento e certo sentimento de desamparo. Remete-nos a alguma coisa com a qual estamos acostumados (lidar com seres vivos, animados), porém numa variante um tanto desconcertante. Como bem pontua Marc Falkenberg (2005: 62), para Jentsch não há situação unheimlich sem que haja um sujeito ignorante dos fatos despreparado para determinadas situações, as quais, para outras pessoas, seriam triviais. É o que ocorre com o leitor de $O$ Homem $d a$ Areia:

No campo da narrativa, um dos dispositivos artísticos mais confiáveis para produzir efeitos insólitos é deixar o leitor incerto de ter um ser humano ou um autômato à sua frente, no caso de uma personagem particular. Isso é feito de tal modo que a incerteza não apareça diretamente no ponto focal de sua atenção, de forma que não lhe é dada ocasião para investigar e clarificar o assunto imediatamente, para que o efeito emotivo particular,

12 "No attempt will here be made to define the essence of the uncanny."

13 "[...] the same impression does not necessarily exert an uncanny effect on everybody."

Pandaemonium, São Paulo, v. 22, n. 38, set.-dez. 2019, p. 122-141 
SILVA, F.; COSTA, S.F. - A imaginação romântica como neurose?

conforme dissemos, fosse assim dissipado rapidamente. Em suas obras de fantasia, E. T. A. Hoffmann repetidamente se serviu desse artifício psicológico com sucesso. (JENTSCH 1997: 13$)^{14}$

À época de Hoffmann, na verdade desde o século XVIII, autômatos eram uma verdadeira obsessão, talvez da mesma forma que robôs são hoje em dia. Possivelmente influenciado pela noção de Descartes e La Mettrie de l'homme-machine - uma que sugeria que o corpo humano poderia um dia ser entendido como um conjunto de operações mecânicas que produzem a vida, assim como relógios ${ }^{15}-$, o impulso analítico da era do Esclarecimento gerou um interesse generalizado pelo aperfeiçoamento da arte de construir esses protorrobôs e tal arte atingiu rápido aperfeiçoamento mediante subsídio de figuras poderosas, como o próprio rei da Prússia. Conta-se que Frederico II gastava horas discutindo com inventores e era fascinado por autômatos, os quais mantinha em seu quarto, "não apenas como meio de ilustrar um organismo" (como esqueletos num laboratório de ciências, por exemplo), "mas também como marionetes políticas, modelos de poder em pequena escala" (FouCAULT 1979: 136). ${ }^{16}$

Em suma: ainda que pensadores e artesãos acompanhassem um processo veloz de sofisticação de bonecos articulados que mexiam membros e olhos por meio de dispositivos mecânicos elaborados, uma pessoa desavisada não saberia o que pensar de tal tecnologia. Segundo Jentsch, tratava-se de um exemplo perfeito para explicar uma situação unheimlich. E. T. A. Hoffmann, como autor com gosto acentuado pelo bizarro, valeu-se em duas ocasiões de personagens aparentemente animadas, mas que mais tarde foram reveladas como bonecos. A mais célebre delas é a amada secreta do protagonista em O Homem da Areia, Olimpia, cujo primeiro encontro cito a seguir.

Nathanael está instalado na casa em frente à de seu professor, o italiano Spallanzani. Após comprar um telescópio, ele descobre à janela do estrangeiro a tal boneca Olimpia, que acredita ser a mulher mais bela do mundo. Na cena citada abaixo,

\footnotetext{
14 "In storytelling, one of the most reliable artistic devices for producing uncanny effects easily is to leave the reader in uncertainty as to whether he has a human person or rather an automaton before him in the case of a particular character. This is done in such a way that the uncertainty does not appear directly at the focal point of his attention, so that he is not given the occasion to investigate and clarify the matter straight away; for the particular emotional effect, as we said, would hereby be quickly dissipated. In his works of fantasy, E. T. A. Hoffmann has repeatedly made use of this psychological artifice with success." Esta é a única ocasião em que Hoffmann é mencionado no ensaio de Jentsch.

${ }^{15}$ Para um tratamento detido da questão, ver Cassirer (2007: 56 et seq).

${ }^{16}$ A citação completa é: "The celebrated automata were not only a way of illustrating an organism, they were also political puppets, small-scale models of power: Frederick, the meticulous king of small machines, well-trained regiments and long exercises, was obsessed with them." Para documentação sobre a mania setecentista por esses protoandroides, ver Wood (2002).
} 
Nathanael está dentro da casa do professor numa reunião social e encontra ocasião a sós com o autômato.

[...] ele mesmo não soube como aconteceu de, assim que a dança começou, ele estar postado bem junto à Olimpia, que ainda não tinha parceiro, e, quase incapaz de balbuciar uma palavra, segurou-lhe a mão. A mão de Olimpia estava fria como gelo; ele sentiu-se estremecer de um tétrico calafrio, fitou Olimpia nos olhos, que para ele brilhavam cheios de amor e desejo, e, naquele instante, foi como se sua gélida mão começasse a pulsar e o ardente sangue da vida se pusesse a correr em suas veias. (HOFFMANN 1963a: 399) ${ }^{17}$

Não há uma palavra sobre estranhamento, ainda que as coisas causem o efeito oposto que deveriam (segurar a mão congelante da boneca fá-lo arder de paixão; ao mirar aqueles olhos ele não vê irradiar nada... nada além de amor). Nathanael a toma nos braços e não duvida em momento algum que se trata de uma pessoa real. Apenas mais tarde, um amigo, Siegmund, tentará alertá-lo:

Ela poderia ser considerada bela se ao seu olhar não faltasse o irradiar da vida, quer dizer, se não lhe faltasse o poder da visão. Seu andar é estranhamente contido, cada movimento parece depender de um maquinismo em que se deu corda. Seu modo de tocar e cantar tem o ritmo sem vida e desagradavelmente correto de uma máquina cantante, e o mesmo vale para a maneira como dança. Essa tal de Olimpia se tornou bastante insólita para nós. Não queremos nada com ela; tivemos a impressão de que apenas fingia ser uma criatura viva e de que escondia um estranho mistério consigo. (op. cit.: 402, grifo nosso) ${ }^{18}$

Para as pessoas saudáveis, a presença de Olimpia torna-se insólita. A rigidez de seus membros contrastada à sofisticação de seus mecanismos, esse meio-termo entre autêntico e artificial é o que causa o estranhamento. O insólito aqui não é um sentimento análogo ao pavor, somente à aflição. Siegmund chama a atenção de Nathanael sem saber que este delira e interage com Olimpia como se fosse viva; eles habitam duas dimensões da realidade bastante diversas. Para Siegmund, o problema com o amigo é sua fascinação pelo autômato, vista como uma ocupação estranha pelos convivas, para os quais seria mais adequado que ele interagisse com pessoas reais.

Quando voltamos ao texto de Jentsch, vemos que sua interpretação do insólito é muito destoante do sentido designado por Hoffmann no trecho destacado. A origem do

\footnotetext{
17 “ "...] er selbst wußte nicht, wie es geschah, daß er, als schon der Tanz angefangen, dicht neben Olimpia stand, die noch nicht aufgefordert worden, und daß er, kaum vermögend einige Worte zu stammeln, ihre Hand ergriff. Eiskalt war Olimpias Hand, er fühlte sich durchbebt von grausigem Todesfrost, er starrte Olimpia ins Auge, das strahlte ihm voll Liebe und Sehnsucht entgegen, und in dem Augenblick war es auch, als fingen an in der kalten Hand Pulse zu schlagen und des Lebensblutes Ströme zu glühen."

18 "Sie könnte für schön gelten, wenn ihr Blick nicht so ganz ohne Lebensstrahl, ich möchte sagen, ohne Sehkraft wäre. Ihr Schritt ist sonderbar abgemessen, jede Bewegung scheint durch den Gang eines aufgezogenen Räderwerks bedingt. Ihr Spiel, ihr Singen hat den unangenehm richtigen geistlosen Takt der singenden Maschine, und ebenso ist ihr Tanz. Uns ist diese Olimpia ganz unheimlich geworden, wir mochten nichts mit ihr zu schaffen haben, es war uns, als tue sie nur so wie ein lebendiges Wesen und doch habe es mit ihr eine eigne Bewandtnis."
} 
SILVA, F.; COSTA, S.F. - A imaginação romântica como neurose?

sentimento, lemos na segunda parte do artigo (op. cit.: 15), é nossa tendência natural de inferir ligações entre as coisas. Ao nos depararmos com um cadáver que não esperávamos ver, logo pensamos que algum dia aquela pessoa esteve viva - e algo de vivo tem de restar ali, por algum motivo. O medo dos mortos advém desse impasse de observadores incautos; um médico treinado, por exemplo, dificilmente seria acometido por qualquer sensação perturbadora no caso. O sentimento não é algo fixo, portanto, mas fruto da ignorância parcial, da falta de maturidade emocional própria de alguém instável como o Nathanael de Hoffmann. Segundo Jentsch e Freud, mais tarde, é Nathanael, e não os convidados, quem termina mentalmente perturbado pelo insólito.

Isso explica, para Jentsch, por que um "filho da natureza" tem a tendência de animar seu mundo com demônios; "crianças pequenas falam com toda a seriedade com uma cadeira, com sua colher, com um trapo velho, e por aí vai” (JENTSCH 1997: 13). ${ }^{19} \mathrm{O}$ animista infere que tem de haver algo por trás da dinâmica das coisas, ainda que ele não veja; o mundo não pode se reduzir à empiria. Povos antigos, que seriam habitantes de uma fase primitiva da civilização humana, igualmente se entretiveram com tais inferências. "Mesmo na altamente cultivada Grécia, uma dríade ainda vivia dentro de cada árvore" (idem). ${ }^{20}$ A questão aqui é uma de experiência. O ser humano, independente da faixa etária ou época em que vive, tem um impulso por controlar seu ambiente. Assim, somente a certeza intelectual seria capaz de prover um "abrigo psicológico na luta pela existência" (Ibidem: 15). O sentimento do unheimlich e as superstições seriam, por conseguinte, frutos de ignorância. Sua extinção não seria uma questão terapêutica, mas educacional.

Jentsch se refere ao conceito exclusivamente na condição de adjetivo (unheimlich) e não como um substantivo abstrato, indicador de um fenômeno singular (Das Unheimliche, como faz Freud). Parte da inovação freudiana deriva daí; "Das Unheimliche [...] corresponde a uma mudança de perspectiva dos sentimentos da pessoa [...] para o fenômeno que causa determinada impressão. Tal mudança transforma "o insólito" numa coisa" (FALKENBERG 2005: 63). ${ }^{21}$ De acordo com a psicanálise freudiana, ele é um

\footnotetext{
${ }^{19}$ Citação completa: "The child of nature populates his environment with demons; small children speak in all seriousness to a chair, to their spoon, to an old rag, and so on [...]."

20 "Even in highly cultivated Greece, a dryad still lived in every tree."

21 "Das Unheimliche [...] corresponds to a shift in perspective from the feelings of the person [...] to the phenomena causing the impression. This shift turns 'uncanny' into a thing"'. A única outra ocasião em que Freud trata do conceito é em Totem e Tabu (1913), um texto escrito entre o lançamento do artigo de Jentsch (1906) e o seu próprio (1919). Na ocasião, unheimlich aparece preponderantemente de modo adjetivado
} 
SILVA, F.; COSTA, S.F. - A imaginação romântica como neurose?

fenômeno da psique humana vindo de um problema de recalque, que provoca um distanciamento da realidade. Ele vem de dentro; ainda que Nathanael tenha provas empíricas de que a amante imaginária, Olimpia, seja uma boneca, isso não altera sua atitude. O mesmo vale para seu trauma de infância: ele vê o assassino do pai no rosto de diversos homens, e não consegue inferir a impossibilidade de que todos sejam o tal homem. "[O insólito] se refere a um recalque verdadeiro de determinado conteúdo por meio do retorno do recalcado, e não à anulação da crença na realidade de tal conteúdo" (FREUD 2012: 28; ver também DIERKS 2006: 206). ${ }^{22}$

A anulação da crença supersticiosa contaria, portanto, como processo esperável da psique conforme o indivíduo amadurecesse. Freud atualiza Jentsch na medida em que considera a possibilidade do desvio neurótico relativo ao insólito e atesta a necessidade de uma terapia para lidar com conteúdos recalcados via experiências traumáticas. ${ }^{23} \mathrm{~A}$ recorrência do sentimento em questão, portanto, apontaria para o indício de um problema maior, oculto na psique de Nathanael desde a infância. Não obstante, como vimos, a atualização freudiana se dá numa direção oposta à que Hoffmann sugere em seu texto quando relaciona o termo unheimlich ao estranhamento vivido por pessoas saudáveis diante da boneca Olimpia.

Há diversas outras lacunas na análise de Freud: para a construção de seu argumento, o autômato Olimpia é um mero sintoma, sem grande participação na narrativa. De fato, o psicanalista deixa de notar uma infinidade de detalhes textuais para os quais a fortuna crítica de Hoffmann tem atentado recentemente (FALKENBERG 2005: 69). Além de errar a grafia do nome de Nathanael (escrevendo "Nathaniel" na primeira versão do ensaio), foge de sua análise dados relevantes de sua própria teoria, tais quais:

(ver FREUD 1922: 25, 30, 31, 33, 115). Sua transformação em fenômeno parece ser uma inovação do final da década de 1910.

22 "Es handelt sich um wirkliche Verdrängung eines Inhaltes und um die Wiederkehr des Verdrängten, nicht um die Aufhebung des Glaubens an die Realität dieses Inhalts."

${ }^{23}$ Freud não trata da terapêutica em seu ensaio, já que o foco é definir um fenômeno psíquico. Mas leiamos o que diz no seguinte trecho: "[O Insólito] diz respeito ao recalque real de seu conteúdo e ao retorno do recalcado" [Es handelt sich um wirkliche Verdrängung eines Inhaltes und um die Wiederkehr des Verdrängten] (FREUD 2012: 28). O termo Verdrängung é central para a terapêutica freudiana pelo menos desde a famosa "Comunicação Preliminar" aos Estudos sobre a Histeria, escritos com Breuer em 1893 (ver FREUD; BREUER 2006: 47). Desde então, os sintomas psíquicos do doente são lidos como conteúdo recalcado convertido em algo diverso de si (Ibidem: 188) e tal conversão deve ser remediada pelo analista que atinja a cura. Daí a belíssima metáfora da mente humana como o monte Etna da mitologia grega: "a parte dividida da mente é 'lançada nas trevas', como os Titãs aprisionados na cratera do Etna, que podem abalar a terra, mais [sic!, mas] jamais emergirem à luz do dia" (Ibidem: 248). 
SILVA, F.; COSTA, S.F. - A imaginação romântica como neurose?

(1) os sintomas do protagonista e recolecção de memórias traumáticas só ocorrem após a visita de Coppola, alter ego do assassino de seu pai;

(2) a volta desse alter ego em diversas formas, ademais, não é algo meramente imaginado por Nathanael, como se se originasse de sua psique instável: desde o início da novela o estranho antagonista é um agente externo na história de vida de Nathanael e sua família. Ele também é visto pelos outros.

Por conseguinte, toda a aplicação de um cenário edipiano às experiências de Nathanael só se torna convincente mediante uma distorção sistemática de dados elementares do enredo (FALKENBERG 2005: 74). Freud demonstra interesse maior em usar (e não dialogar com) o texto literário, valendo-se de sua licença poética (ou melhor, médica) para ilustrar sua própria teoria.

Isso é algo esperável quando se trata do grande teórico da psicanálise, escrevendo para o renomado periódico psicanalítico Imago. Contudo, quando nos estudos literários a interpretação freudiana se torna canônica, a fortuna crítica da literatura fantástica, principalmente, termina por reduzir a complexidade do programa estético hoffmanniano a um correlato do freudiano. Aqui reside um equívoco que vem sendo repetido até hoje na fortuna crítica em língua portuguesa, já referida acima.

Entretanto, sobretudo na obra tardia de Hoffmann, a imaginação romântica não é sinônimo de indício de neurose; ela exerce, simultaneamente, a função de refúgio libertador para seus protagonistas, outsiders (como o foi o Hoffmann histórico) e de postura de resistência contra a indolência cultural da Alemanha na era da Restauração (GÜNZEL 1984: 8). O maior inimigo destes não é a loucura, mas seu oposto, a normalidade de um mundo devastado pelo olhar analítico das ciências modernas, juntamente com um gosto por interpretações totalizantes dos mistérios da natureza, do qual a própria psicanálise freudiana será herdeira direta no século XX. É no mínimo irônico o fato de que Hoffmann, o grande inimigo da sentenciosidade dos filósofos, teria sido um antagonista de Freud caso tivessem vivido na mesma época.

Sua versão da imaginação romântica é avessa ao que lemos no artigo de Freud; deste ela se distancia tanto cronologicamente quanto em espírito, afiliando-se ao animismo, um estágio em que o homem ainda sabia idear um mundo com conexões mágicas e criaturas fantasiosas. Hoffmann, ao nos exibir personagens desvairadas, portase menos como um terapeuta e mais como um mensageiro da ambivalência inerente à existência humana: “Talvez assim você venha a acreditar, ó meu leitor, que não há nada 
SILVA, F.; COSTA, S.F. - A imaginação romântica como neurose?

mais maravilhoso e insano do que a vida real, e que esta, somente o poeta consegue captar como um obscuro reflexo num espelho embaçado", lemos num interlúdio de $O$ Homem da Areia. ${ }^{24} \mathrm{O}$ cientista não consegue nem ao menos chegar a essa imagem imperfeita.

\section{Animismo versus antifetichismo: críticas a Freud como}

\section{contribuições para uma nova apreciação de Hoffmann}

Ainda que, no ensaio em questão, Freud fale sobre a mentalidade animista sem demora, apenas para fins de exemplo, foi justamente este um dos aspectos mais criticados no texto por autores recentes. Freud (2012: 21) remete a esse estranho conceito de Animismus (em uma época em que ainda era um neologismo) dizendo: animismo é o estágio intelectual característico de uma fase pré-científica e encantada na civilização. Ele não é apenas uma crença enterrada num passado remoto já que, em termos filogenéticos, volta a nos visitar quando nos deparamos com o insólito, ainda que brevemente. Para o autor, a recorrência passageira do sentimento de estranhamento em nós, indivíduos modernos e bem resolvidos, é um traço de uma constituição primeva da civilização. O vínculo com nossos antepassados animistas nos levaria a achar, por um instante, que as coincidências não são exatamente coincidências e que talvez houvesse chance de uma boneca como Olimpia ter uma fagulha de vida dentro de si (DIERKS 2006: 206). Vítimas de experiências traumáticas recalcadas, como Nathanael, podem ficar presas a ideias oriundas desse imaginário ultrapassado, algo que, em pessoas saudáveis, aos poucos desapareceria conforme se convencessem de que não precisam mais de deuses, espíritos e nada além de sua própria autonomia.

Como consequência, o mundo moderno - ao contrário do mundo "maravilhoso e insano" de Hoffmann (1963a: 387) - é um ambiente de desencantamento, no qual todos os mistérios se perdem e nada mais deveria nos inquietar. Esse não é um resultado a ser lamentado, mas derivação do processo civilizatório. Seguindo o gosto novecentista por metáforas biológicas, em O Insólito (2012 [1919]) e Totem e Tabu (1922 [1913]), Freud compara a consolidação da atual civilização ocidental, científica e autoconsciente, com a chegada da idade adulta em um ser humano. Assim como um homem crescido, o Ocidente

\footnotetext{
24 "Vielleicht wirst du, o mein Leser! dann glauben, daß nichts wunderlicher und toller sei als das wirkliche Leben und daß dieses der Dichter doch nur, wie in eines matt geschliffnen Spiegels dunklem Widerschein, auffassen könne." (HOFFMANN 1963a: 387)
} 
SILVA, F.; COSTA, S.F. - A imaginação romântica como neurose?

perde suas crenças em deuses e forças incomensuráveis que antes entreteriam sua imaginação infantil. Se ele perde o tom jocoso e vivaz de seus gestos, tal perda é compensada por sensatez e autocontrole. O homem moderno não mais precisa de deuses que salvem sua alma ou de garantias transcendentais que determinem suas ações; e é só aí que se torna, de fato, responsável por seu destino.

Desafios a tal postura (bastante etnocêntrica) de Freud reformulam a problemática propondo o animismo como uma alternativa tão eficiente e legítima quanto o cientificismo esclarecido que o psicanalista propôs. Para críticos recentes como Latour (2002) e Stengers (2017), muitos teóricos da Modernidade cometeram um erro metodológico ao se julgarem intelectualmente superiores ao modelo de humano do passado que adora estatuetas ou fala com espíritos. Enquanto julga este como dependente de uma realidade imaginada, povoada por espíritos ou ligações místicas entre as coisas, o cientista moderno se propõe como um agente autônomo no mundo. Ele não precisa de mediações para interagir com seu exterior - supostamente há uma transparência ideal entre suas intenções e atuação (LATOuR 2002: 29). Cá reside a prepotência autoenganadora desse grupo que Latour chama de "antifetichista": os que se enganam na medida em que ignoram que são também submetidos a forças exteriores ou paradigmas científicos para interpretar e agir no mundo, da mesma forma que o feiticeiro vodu precisa de seus artefatos mágicos. Latour (Ibidem: 15) conclui: “a crença [em espíritos] não é um estado mental" - nem indicativo necessário dum estágio na evolução intelectual - "mas um efeito das relações entre os povos".

O interesse de Latour não parece ser de verificar epistemologicamente se antifetichistas modernos têm o pé mais ou menos fincado na realidade. Antes, ele afirma que os modernos também constroem seus próprios fetiches (Ibidem: 25), de forma que a divisão entre antifetichistas (pré-modernos) e fetichistas (modernos) se revela como fruto de uma problemática falsa. Se somos modernos de fato, substancialmente diferentes dos homens e mulheres do passado, isso ocorre por um motivo diverso. Não tem a ver com o quanto deixamos que a imaginação determine nossas práticas.

Stengers (2017: 2) vai além para propor a atitude antifetichista como um mecanismo de controle "no qual os conceitos filosóficos serviam para justificar a colonização e a divisão por meio da qual uns [os modernos] se sentiam livres para estudar e categorizar outros [os pré-modernos] - uma divisão que ainda persiste". Ainda persiste, de acordo com o ensaio originalmente publicado em 2012. O desencantamento do mundo 
SILVA, F.; COSTA, S.F. - A imaginação romântica como neurose?

pela ciência sóbria e dissecadora, derivado dessa negação radical da postura animista, é algo que Stengers contabiliza como desastroso para a coesão do mundo multicultural de hoje. Ele tampouco é um desencantamento necessário (como queriam Freud/Jentsch), mas mero "produto de um processo de colonização" (Ibidem: 4), da vitória da mentalidade europeia sobre outras culturas até hoje animistas. ${ }^{25}$ Essa vitória, é claro, não se traduz como resultado de um debate de ideias, mas de "erradição cultural e social [...] cometido em nome da civilização e da razão" (Ibidem: 9). Nessa chave, naturalizar o cientificismo seria, portanto, uma atitude curiosamente desprovida de rigor intelectual. A naturalização de uma verdade absoluta é a forma suprema do fetichismo: em vez de deuses, arquitetamse escalas evolutivas em que se justifica meu valor preponderante sobre aqueles infiéis ignorantes.

O mesmo valeria num nível de relações psíquicas e individuais. Em um importante trecho de seu ensaio, Stengers (Ibidem: 6) se refere ao fetichismo velado de Freud:

Chegou-se a propor, inclusive, que a psicanálise não era a "praga" subversiva de que Freud se vangloriava, mas sim uma restauração da ordem, já que ajudava a explicar curas misteriosas, a "lucidez" magnética e outras manifestações demoníacas categorizadas como puramente humanas. Em nome da Ciência, ela estaria decifrando uma nova causa universal.

A verdade da psicanálise depende de que aceitemos a "lucidez" como um valor acompanhado de sinal positivo (+) e o "insólito" como algo diametralmente oposto, habitante dos monturos da irracionalidade e afecções lúbricas. Quando Stengers propõe a reativação do animismo, ela o faz contra a "ideia da triste relatividade de todas as verdades". "Reativar significa reativar [reivindicar, recuperar = reclaim] aquilo de que fomos separados" por força de uma campanha colonizadora das mentalidades. É devolver a "capacidade de interpretar tanto a bruxaria como a caça às bruxas em termos de construções" (Ibidem: 8-9).

As críticas de Latour e de Stengers nos permitem voltar aos ensaios de Jentsch e Freud e identificar a sutil contradição de ambos terem escolhido uma novela de E. T. A. Hoffmann para defender a tese antifetichista, antianimista. De fato, eles escolheram um dos poucos textos de Hoffmann em que a imaginação é retratada como fonte de destruição psíquica. "O campo do horripilante e suprassensível, o refúgio dos sonâmbulos, duplicatas fantasmas e autômatos era há tempos um domínio dos românticos" (GÜNZEL

\footnotetext{
${ }^{25}$ A rigor, em Taiwan e Bali, na Papua Nova Guiné e no Havaí, além de mais em uns tantos povos africanos, o animismo persiste em forma original ou mesclada a religiões majoritárias, tendo sido capaz, portanto, de sobreviver ao processo de modernização intato.
} 
SILVA, F.; COSTA, S.F. - A imaginação romântica como neurose?

1984: 13$)^{26}$ - e certamente Hoffmann se alimentou dele na condição de pupilo, gerando uma versão de contos fantásticos e fantasmagóricos que se provaram mais impactantes do que a dos próprios criadores da literatura de horror alemã, a Schauerliteratur (nomes menos expressivos como Spieß, Apel, Schulze e Klingemann). No entanto, a parcela fantasmagórica da obra daquele foi fruto de uma fase de crises pessoais durante a qual Hoffmann morou em Bamberg, entre 1809 e 1813, período que seu biógrafo Klaus Günzel (1984: 147-167) documentou muito bem. Dali em diante o autor abandonaria o elemento sobrenatural cada vez mais e passaria a escrever a serviço de uma análise social mais objetiva. Naquele momento, "ele não encontrava o insólito, o grotesco e anormal apenas na literatura, mas ainda mais diretamente em seus próprios arredores" (Ibidem: 14). ${ }^{27} \mathrm{O}$ insólito deixa de ser produto de um cérebro doente - da neurose do paciente, como a interpretação psicanalítica propõe - para se reverter em símbolo da dissonância entre o equilíbrio psíquico do indivíduo e condições reais que o ameaçam na Alemanha da Restauração.

\section{Romantizar é reativar o animismo? $\bigcirc$ caso de Des Vetters}

\section{Eckfenster (1822)}

Como vimos, o neurótico/primitivo freudiano doa onipotência ao pensamento, superenfatizando a realidade psíquica em detrimento da realidade material (FREUD 2012: 25; FREUd 1922: 115). Como romântico, Hoffmann afirma justamente o contrário; em textos posteriores, ele volta a tematizar o papel da imaginação na construção das realidades pessoais. Deles, destacarei o caso de A Janela de Esquina do meu Primo (Des Vetters Eckfenster, 1822), cujo roteiro resumo na sequência.

O personagem-narrador se encontra na Berlim dos anos 1820, a então mais populosa cidade da Prússia, e visita um primo um pouco mais velho. O homem tornarase há pouco tempo inválido e passeia de lá para cá em um pequeno quarto sobre sua cadeira de rodas, instalando-se à janela de onde tem uma vista privilegiada da cidade. Uma vez que o narrador chega, descobre que o primo passa por uma crise pessoal: como

\footnotetext{
26 "Das fragwürdige Feld des Schauerlichen und Übersinnilichen, das Refugium der Somanmbulen, Doppelgänger und Automaten war längst eine Domäne der Romantiker [...]."

27 " $[\mathrm{Zu}$ dieser Zeit] fand er doch das Unheimliche, Fratzenhafte und Abnorme nicht nur in der Literatur, sondern mehr noch direct in seiner Umwelt vor."
} 
SILVA, F.; COSTA, S.F. - A imasinação romântica como neurose?

homem com pretensões artísticas, ele embate um writer's block. Uma habilidade sua, porém, permanece intata: "a doença mais grave não pode impedir o rolar de rodas vertiginoso de sua fantasia" (HOFFMANN, 1963b: 742). ${ }^{28}$ Isto é, sua visão de artista, capaz de animar uma realidade que para pessoas comuns parece árida e trivial, nunca foi extinguida. Essa é a única capacidade que devolve ao inválido sua esperança, doando-lhe "força vital recém-desperta" (Ibidem: 743). ${ }^{29}$

A partir daí, inicia-se um exercício conjunto por parte dos dois primos: o narrador, que admite ser um homem sem qualquer talento para poetizar o mundo, aprende com o primo artista a transformar uma cena aparentemente trivial em algo repleto de significados. Se inicialmente ele começa o texto afirmando que "[t] odo o mercado parecia uma única massa humana bem esmagada. Aquele mercado não oferecia nada além da visão de um tumulto híbrido e confuso de um povo empenhado numa atividade sem sentido" (Ibidem: 744$)^{30}$, ao fim da experiência de interpretar cena a cena daquele enorme quadro da vida berlinense, a personagem-narrador será capaz de reanimar a cena, enxergando nela "um retrato fiel da vida em eterno movimento" (Ibidem: 772). ${ }^{31} \mathrm{O}$ mesmo narrador remete aqui a um tópos recorrente no romantismo, o do "olho que realmente enxerga" (Ibidem: 744), ${ }^{32}$ que reativa as conexões anímicas entre as coisas, por trás dos fatos da vida. Num mundo moderno desencantado, da vida organizada em torno do dinheiro e do status social, os heróis das narrativas hoffmannianas são outsiders que perambulam as calçadas de Berlim ébrios e semidelirantes, interagindo com um mundo reencantado condizente com sua escolha por um estilo de vida avesso à sisudez pela qual os prussianos eram conhecidos, como dita o estereótipo. Alguns desses heróis são vítimas de sua própria insanidade (como o já citado Nathanael de $O$ Homem da Areia), outros são elevados a símbolo de resistência, ao perfil dos que devolverão a este mundo inerte sentidos imanentes. A Janela de Esquina do meu Primo, conto escrito apenas dois meses antes da morte do autor, pode ser visto como um texto programático do Romantismo

\footnotetext{
28 “ [...] die schwerste Krankheit vermochte nicht den raschen Rädergang der Phantasie zu hemmen.”

29 "[...] neuerweckte Lebenskraft."

30 "Der ganze Markt schien eine einzige, dicht zusammengedrängte Volksmasse, [...] Jener Markt bietet dir nichts dar als den Anblick eines scheckichten, sinnverwirrenden Gewühls des in bedeutungsloser Tätigkeit bewegten Volks.”

31 " [...] ein treues Abbild des ewig wechselnden Lebens."

32 "Auge, welches wirklich schaut”. Ralph Waldo Emerson, do outro lado do Atlântico, tinha uma metáfora semelhante ao comparar-se com um globo ocular transparente: "I become a transparent eye-ball; I am nothing; I see all; the currents of the Universal Being circulate through me; I am part or parcel of God" (EMERSON 1983: 10).
} 
SILVA, F.; COSTA, S.F. - A imaginação romântica como neurose?

alemão: ele é um grande resumo da prática artística de Hoffmann que, embora um representante tardio do movimento, relegou-nos textos que se tornaram modelares.

"O mundo deve ser romantizado [romantisiert]", lemos num famoso fragmento do teórico do primeiro Romantismo, Novalis.

Assim volta-se a encontrar seu sentido primevo. Romantizar nada mais é do que uma potenciação qualitativa. [...] Ao conferir alto sentido ao que é comum, uma aparência misteriosa ao habitual, a dignidade do desconhecido ao conhecido, ares imortais ao mortal, romantizamo-lo. (NovALIS 1978: 334) ${ }^{33}$

Para o romântico tardio Hoffmann, porém, essa romantização não deve se resumir a um mero exercício de livre-associação, mas ser fruto de negociação de significados (como ocorre entre os dois primos) e reflexo de um empenho de aperfeiçoamento do olhar. Não do olhar analítico, num sentido redutor do termo, mas de uma forma de enxergar disposta a cavoucar as estruturas que movem o mundo ao nosso redor. Trata-se também da contemplação de perspectivas múltiplas sobre a mesma coisa, como a visão que contempla "tanto a bruxaria quanto a caça às bruxas" de que fala Stengers (2017: 9). A postura romantizadora tem seu lado obscuro - e Hoffmann escreveu um volume inteiro contendo histórias sobre os demônios da imaginação, suas famosas Nachtstücke ${ }^{34}$-, uma vez que sua imagem da experiência humana é ambivalente.

Em O Homem da Areia é difícil até mesmo dizer quem é o narrador, o que contradiz a leitura freudiana do animismo como uma pretensa onipotência do pensamento. O tecido da realidade, propõe o texto hoffmanniano, é reconstruído entre duas ou mais pessoas sem que se chegue a uma harmonia: é aquilo com que os leitores se confrontam ao ler os dois primos interpretando a mesma cena de formas distintas em Des Vetters Eckfenster, ou ao ler os disparates do louco Nathanael e as exortações do empirista Siegmund em Der Sandmann. Os exemplos são vários: o mesmo se passa em demais narrativas da série Die Seraphionsbrüder (1819-1821).

A intenção aqui não é, enfim, esgotar a totalidade dessa extensa obra a partir de listas. Um padrão, porém, pode ser resgatado: a realidade última no mundo de Hoffmann deve ser entendida como um quadro de contrastes. Tudo está permeado por seu oposto, se olharmos bem, e suscitará ora maravilhamento ora estranhamento (GÜNZEL 1984: 8-

\footnotetext{
33 "Die Welt muß romantisiert werden. So findet man den ursprünglichen Sinn wieder. Romantisieren ist nichts als eine qualitative Potenzierung. [...] Indem ich dem Gemeinen einen hohen Sinn, dem Gewöhnlichen ein geheimnisvolles Ansehn, dem Bekannten die Würde des Unbekannten, dem Endlichen einen unendlichen Schein gebe, so romantisiere ich es"

${ }^{34}$ Refiro-me a Nachtstücke herausgegeben von dem Verfasser der Fantasiestücke in Callots Manier, publicação em duas partes (1816-1817). O Homem da Areia é a novela que abre o volume um.
} 
SILVA, F.; COSTA, S.F. - A imaginação romântica como neurose?

9). Tendo isso em consideração, para o último Hoffmann, aprender a enxergar além do véu das interpretações normalizadas seria a única forma de comunicação honesta, de escrever uma literatura honesta.

É nesse sentido que o conto final de Hoffmann se constitui como um "missing link entre a poética romântica e a realista" (LIEBRAND 2015: 193). ${ }^{35}$ Trata-se do texto de quem infelizmente não viveu o bastante para nos relegar demais escritos expressivos dessa postura. Nela encontramos uma mostra de que uma cultura literária que não abra mão de antigos significados transcendentes, da capacidade de interação multimodal com o mundo, não deve ser reduzida a um mero traço da mentalidade animista, primitiva, o que, a propósito, é uma preocupação legítima desde o início da Modernidade.

\section{Referências bibliográficas}

BLOOM, H. Freud and the sublime: a catastrophe theory of creativity. In: ELLMANN, Maud (ed.). Psychoanalytic Literary Criticism. London: Longman, 1994. p. 173-195.

CASSIRER, E. Die Philosophie der Aufklärung. Hamburg: Felix Meiner, 2007.

Dierks, M. Das Unheimliche (1919). In: LothMANN, H.; PFeIFFER, J. (org.). Freud-Handbuch: Leben, Werk, Wirkung. Stuttgart: J. B. Metlzer, 2006. p. 204-207.

EMERSON, R. W. Nature. In: EMERSON, R. W. Essays \& Lectures. New York: The Library of America, 1983. p. 5-50.

FALCATO, A. C. Um amor circular: reflexões sobre o unheimlich em Freud e Hoffmann. In: Existência e Arte, São João del-Rei, n. 7, 2012, p. 200-213.

FALKenBerG, M. Rethinking the uncanny in Hoffmann and Tieck. Bern: Peter Lang, 2005.

Foucault, M. Discipline and Punish. New York: Vintage Books, 1979.

FREUD, S. Das Unheimliche (1919). Roma: Europäischer Literaturverlag, 2012.

FREUD, S. O Inquietante. In: Obras Completas de Sigmund Freud. v. 14. São Paulo: Companhia das Letras, 2010. p. 328-376.

FREUD, S. O Estranho (1919). In: História de uma neurose infantil. Rio de Janeiro: Imago, 1996. p. 233-270.

FREUD, S. Totem und Tabu: einige Übereinstimmungen im Seelenleben der Wilden und der Neurotiker. 3. ed. Leipzig: Internationaler Psychoanalytischer Verlag, 1922.

FrEUD, S. Das Unheimliche. Imago, Wien, n. 5, v. 5/6, 1919, p. 297-324.

FREUD, S.; BREUER, J. Estudos sobre a Histeria. In: FREUD, S. Edição Standard brasileira das obras psicológicas completas. v. 2. Rio de Janeiro: Imago, 2006.

GüNZEL, K. (org.). E. T. A. Hoffmann: Leben und Werk in Briefen Selbstzeugnissen und Zeitdokumenten. Berlin: Verlag der Nation, 1984.

Herrmann, B. Der Sandmann (1816). In: Lubkoll, C.; Neuermeyer, H. (ed.). E. T. A. Hoffmann Handbuch: Leben - Werk - Wirkung. Stuttgart: J. B. Metzler, 2015. p. 48-53.

Hoffmann, E. T. A. A Janela de Esquina do meu Primo. Trad. Maria Aparecida Barbosa. São Paulo: Cosac Naify, 2010.

35 “[Des Vetters Eckfenster stellt] einen missing link zwischen romantischer und realistischer Poetik dar."

Pandaemonium, São Paulo, v. 22, n. 38, set.-dez. 2019, p. 122-141 
SILVA, F.; COSTA, S.F. - A imaginação romântica como neurose?

HoffMann, E. T. A. O Homem da Areia. In: Cesarotto, Oscar. No olho do outro: "O Homem da Areia" segundo Hoffmann, Freud e Gaiman. São Paulo: Iluminuras, 1996. p. 17-50.

Hoffmann, E. T. A. Contos fantásticos. Trad. Claudia Cavalcanti. Rio de Janeiro: Imago, 1993.

Hoffmann, E. T. A. Poetische Werke in sechs Bänden. v. 2. Berlin: Aufbau Verlag, 1963a. p. 371-413.

Hoffmann, E. T. A. Poetische Werke in sechs Bänden. v. 6. Berlin: Aufbau Verlag, 1963b. p. 742-775.

JeNTSCH, E. On the psychology of the uncanny (1906). Trad. Roy Sellars. Angelaki, v. 2, n. 1, 1997, p. 7-16.

LATOUR, B. Reflexão sobre o culto moderno dos deuses fe(i)tiches. Florianópolis: EDUSC, 2002.

Liebrand, C. Des Vetters Eckfenster (1822). In: LubKoll, C.; NeuERMEYER, H (ed.). E. T. A. Hoffmann Handbuch: Leben - Werk - Wirkung. Stuttgart: J. B. Metzler, 2015. p. 191193.

MedinA, F. P. Freud e a estética da estranheza. Literartes, São Paulo, n. 7, 2017, p. 285-297.

Novalis, F. H. Werke, Tagebücher und Briefe Friedrich von Hardenbergs. Das philosophischtheoretische Werk. v. 2. Herausgegeben von H. Joachim Mähl. München: Carl Hanser Verlag, 1978.

OliveIRA, I. M. O Autômato: uma figura da paixão. Agora, Rio de Janeiro, v. 20, n. 2, 2017, p. 371-387.

RoYLE, N. The Uncanny. Manchester: Manchester University Press, 2003.

SAntos, A. B. G. E. T. A. Hoffmann e o conto fantástico O Homem da Areia: uma breve elucidação. Pesquisa em Foco, São Luís, v. 17, n. 1, 2009, p. 52-59.

StEnGERS, I. Reativar o animismo. Belo Horizonte: Chão da feira, 2017. (Caderno de Leituras, n. 62)

WoOD, G. Living dolls: a magical history of the quest for mechanical life. The Guardian, 16 fev. 2002. Disponível em: https://www.theguardian.com/books/2002/feb/16/ extract.gabywood. Acesso em: 29 maio 2018.

Recebido em 28 de janeiro de 2019 Aceito em 01 de março de 2019 